\title{
Original article (short paper) \\ 7-week aerobic exercise training reduces adipocyte area and improves insulin sensitivity in Wistar rats fed a highly palatable diet
}

\author{
Nádia F. Garcia \\ Carmem P. Valgas da Silva \\ Maycon Jr. Ferreira \\ Universidade Estadual Paulista “Júlio de Mesquita Filho”, Rio Claro, SP, Brasil \\ Leandro K. Oharomari \\ Universidade Estadual Paulista "Júlio de Mesquita Filho”, Araraquara, SP, Brasil \\ Thalita Rocha \\ Universidade São Francisco, Bragança Paulista, SP, Brasil \\ Camila de Moraes \\ Universidade de São Paulo, Ribeirão Preto, SP, Brasil
}

\begin{abstract}
The aim of this study was to evaluate the effect aerobic exercise training on fat pad mass, adipocyte size, leptin release and insulin sensitivity in rats fed with high fat-palatable diet. Twenty-four male Wistar rats (250-260g) were divided into four groups: sedentary control (CTR/SD), trained control (CTR/TR), obese sedentary (OB/SD) and obese trained (OB/TR). Obese groups were fed with high fat-palatable diet (27\% of fat) and control groups fed with AIN-93. Our results showed that aerobic exercise training was effective to reduce body weight and epididymal fat mass in CTR/TR and OB/TR. Insulin and glucose levels were increased in OB/TR compared with OB/SD. Aerobic exercise training reduced the average area of adipocytes in CTR/TR and OB/TR and it was associated with reduced plasma insulin and leptin. In conclusion, 7-week aerobic exercise training reduces adipocyte area and improves insulin sensitivity and leptin levels in high fat-palatable diet-fed Wistar rats.
\end{abstract}

Keywords: aerobic exercise training, high fat diet, insulin, leptin.

\section{Introduction}

The prevalence of obesity is rising around the world and it has been seen as a global health problem. The modern lifestyle, with easy access to food and technological facilities, increases the risk of obesity development. Besides, overfeeding of saturated fat and sucrose are associated with fast white adipose tissue gain (Ma et al., 2011; Sampey et al., 2011). Excessive body fat mass has a negative impact on health that has been related to the development of type 2 diabetes mellitus, insulin resistance, non-alcoholic fatty liver disease and cardiovascular disease (Galic, Oakhill, \& Steiberg, 2010).

More than an energy storage, the adipose tissue acts as an endocrine organ releasing different substances that participates in different physiological processes such as tumor necrosis factor alpha (TNF-a), interleukin 6 (IL-6) and leptin (Hotamisligil et al.,1993; Zhang et al.,1994; Weisberg et al., 2003). Leptin is an adipokine that was originally identified as a key molecule in the regulation of food intake and body weight. Circulating leptin levels are proportional to body fat mass and obese individuals are resistant to leptin action (Iikuni, Lam, Lu, Matarese, \& La Cava, 2008).

Studies in adipocyte cell culture have provided strong support for the role of hypoxia, induced by adipocyte hypertrophy, to modulate the overproduction of inflammation-related adipokines as IL-6, IL1- $\beta$ and leptin (Wood, De Heredía,Wang \& Trayhurn, 2009).

There is an inverse correlation between adipocyte volume and dyslipidemia, insulin resistance and fasting or post-prandial hyperglycemia (Weisberg et al., 2003). Insulin deficiency may also affect the lipid metabolism affecting several other organs such as blood vessels, brain, pancreas, bone mass, and others (Rask-Madsen \& Kahn, 2012). Furthermore, it is well established that obesity is associated with a chronic low-grade inflammation of the adipose tissue (Henninger,Eliasson, Jenndahl \& Hammarstedt, 2014; Vachharajani, \& Granger, 2009). Weisberg et al. (2003) and Xu et al. (2003) demonstrated that macrophage infiltration in adipose tissue is related to obesity and insulin sensitivity, and these conditions are associated to the development of type 2 diabetes mellitus and insulin resistance. 
Epidemiological and clinical studies have been shown that physical exercise is an important approach in preventing and for treatment of many cardio metabolic diseases, such as arterial hypertension and type 2 diabetes mellitus. Physical exercise exerts important adaptations in skeletal muscle and adipose tissue metabolism (Ciolac \& Guimarães, 2004; Gordecke \& Micklesfield, 2014; Guimarães, Duque, De Carvalho, De Moraes \& Carmo, 2007, Horská, Kucerova, Suchy \& Kotolova, 2014). Thus, considering the negative effect of excessive fat mass on the metabolism, the aim of this study was to evaluate the effect of 7-weeks of aerobic exercise training in fat pad mass, adipocyte size and insulin sensitivity in rats fed with high-palatable diet.

\section{Methods}

\section{Animals and experimental conditions}

Twenty-four male Wistar rats (weighting 250-260g) were obtained from Central Animal Facility (University of São Paulo, campus of Ribeirão Preto) and divided into four groups: sedentary control (CTR/SD), trained control (CTR/TR), obese sedentary $(\mathrm{OB} / \mathrm{SD})$ and obese trained $(\mathrm{OB} / \mathrm{TR})$.

Animals were housed in polypropylene cages $(41 \times 34 \times 30$ $\mathrm{cm}$ ) containing three animals in each, with ad libitum access to water and food, kept on a $12 \mathrm{~h}$ light/dark cycle. Obese groups were fed with high-palatable diet (carbohydrate: 53\%, protein: 20\% and fat: $27 \%$ ) and Control groups were fed with AIN-93 (carbohydrate: $64 \%$, protein: $20 \%$ and fat: $16 \%$ ). High-palatable diet and AIN-93 are isocaloric $(16.8 \mathrm{~kJ} / \mathrm{g})$. The experiment lasted 11 weeks. Animals were fed for 4 weeks prior to exercise training that was carried out for a further 7 weeks. Trained rats rested during 48 hours prior to euthanasia. Animals were euthanized by decapitation without previous anesthetic procedure after 12 hours fasting overnight.

All procedures were reviewed and approved by the Ethics Committee on Animal Use in Research (CEUA/PUSP-RP protocol number 10.1.1290.53.5) in compliance with the US National Institutes of Health Guide Care and Use of Laboratory Animals.

\section{Exercise Training Protocol}

Before starting exercise training, all rats underwent an adaptation period attempting to minimize the potential stress from equipment and effort (for details see Table 1).

Table 1. Adaptation scheme to treadmill exercise.

\begin{tabular}{cccccc}
\hline $\begin{array}{c}\text { Exercise } \\
\text { session }\end{array}$ & 1st & 2nd & 3rd & 4th & 5th \\
\hline $\begin{array}{c}\text { Speed } \\
(\mathrm{m} / \mathrm{min})\end{array}$ & 5 & 5 & 10 & 10 & maximum \\
$\begin{array}{c}\text { Duration } \\
(\mathrm{min})\end{array}$ & 30 & 60 & 30 & 60 & test \\
\hline
\end{tabular}

Training speed was determined after a maximum incremental exercise test (adapted from Hohl et al., 2009), which began at 11.6 $\mathrm{m} / \mathrm{min}$ and increased by $1.6 \mathrm{~m} / \mathrm{min}$ every 2 minutes until $20 \mathrm{~m} / \mathrm{min}$. Subsequently, the speed was increased by $3.2 \mathrm{~m} / \mathrm{min}$ and rats ran until exhaustion (determined when the animal touched the bottom of the bay five times within one minute). The maximal speed (Smax) was considered to be the speed at which exhaustion occurred.

Training intensity progressively increased from $40 \%$ ms on the first week, $50-55 \%$ from the $2^{\text {nd }}$ to $4^{\text {th }}$ week and $60 \%$ from the $5^{\text {th }}$ to $7^{\text {th }}$ week. Exercise sessions last 60 minutes, 5 days a week, for 7 weeks. Rats were trained on a treadmill with individual lanes designed for small animals (Gesan, São Paulo, Brazil).

\section{Body Weight, Food Intake and Epididymal Fat}

Body weight gain was measured weekly and food intake was controlled daily. At the end, epididymal fat was removed; weighed and small fragments were prepared for histological analyses.

\section{Adipose Tissue Histology}

Fragments of adipose tissue were maintained for 24 hours in paraformaldehyde (4\%), processed for dehydration (alcohol) diafanization (xylene), infiltration (paraffin) and included in paraffin. Histological sections of $4 \mu \mathrm{M}$ were stained with hematoxylin-eosin (HE) for morphological evaluation. Images (20x zoom) were obtained using a camera (Olympus QColor 3, Olympus America, USA) connected to the microscope (Olympus BX51, Olympus, Japan). ImageJ software (National Institute of Health, USA) was used to determine adipocyte surface area.

\section{Biochemical Parameters}

Blood samples were collected and centrifuged for 15 minutes at $3000 \mathrm{rpm}$. Serum was used to determine glucose concentration using colorimetric method (Labtest commercial kit, Brazil). Leptin and insulin concentration were determined in plasma using Luminex ${ }^{\circledR}$ technology (panel Milliplex RADPK-81K, Millipore, USA).

\section{Statistical analysis}

Data are expressed as mean \pm standard error mean (SEM) for $\mathrm{n}$ experiments. Analysis of variance (two-way ANOVA) followed by Bonferroni post-hoc test were done using GraphPad Prism software. Significance was considered at 5\% $(P<0.05)$.

\section{Results}

\section{Body weight, epididymal fat and food intake}

Body weight was significantly reduced in CTR/TR group (about 33\%) as compared with CTR/SD group and similar result 
was found in $\mathrm{OB} / \mathrm{TR}$ compared with $\mathrm{OB} / \mathrm{SD}$. As expected, the $\mathrm{OB} / \mathrm{SD}$ showed an increase (about $32 \%$ ) in epididymal fat compared with the CTR/SD group. On the other hand, trained groups had $40 \%$ less epididymal fat mass than sedentary groups. A lower food intake was observed in both trained groups compared with sedentary groups (CTR/TR: $-12 \%$ and OB/TR: $-26 \%$ ) as well as in $\mathrm{OB} / \mathrm{SD}(-28 \%)$ compared with the CTR/SD group. Data are represented in Figure 1.

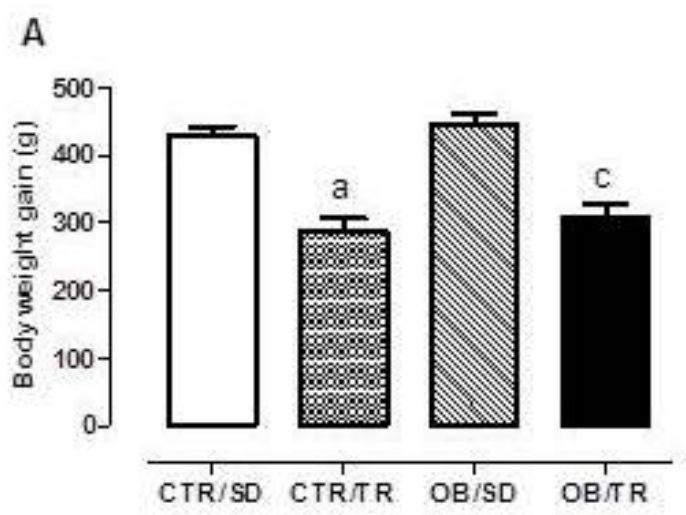

B
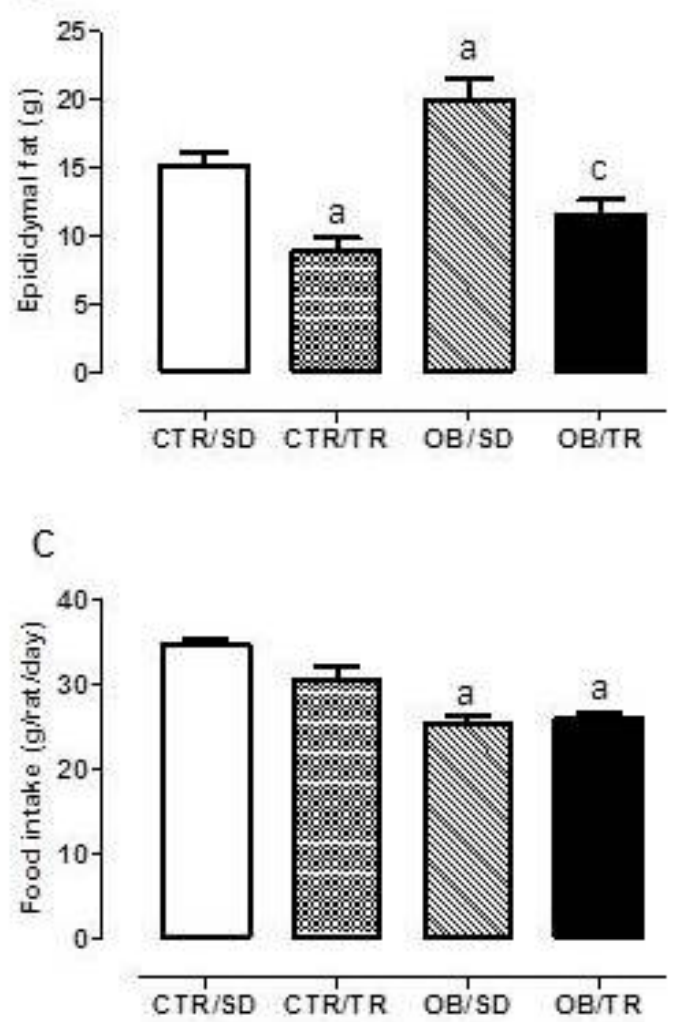

Figure 1. Body weight gain (panel A), epididymal fat pad (panel B) and daily food intake (panel C) control sedentary (CTR/SD), control trained (CTR/TR), obese sedentary $(\mathrm{OB} / \mathrm{SD})$ and obese trained $(\mathrm{OB} /$ $\mathrm{TR})$. Data are mean $\pm \mathrm{SEM}$. ANOVA two-way, Bonferroni post test

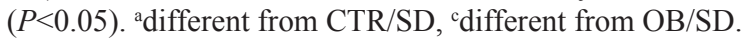

\section{Fasting glucose, Insulin and Leptin}

The high palatable diet intake lead to higher levels of blood glucose (about 15\%), insulin (about 54\%) and leptin (103\%) in the $\mathrm{OB} / \mathrm{SD}$ group compared with $\mathrm{CTR} / \mathrm{SD}$. Exercise training prevented blood glucose increase in the OB/TR group that showed glucose concentration lower than the OB/TR group. Interestingly, we found that CTR/TR group had lower insulin (about 45\%) and leptin (57\%) compared with CTR/SD, similar result was seen in OB/TR that had 52\% less insulin and $81 \%$ less leptin than the OB/SD group (Figure 2).
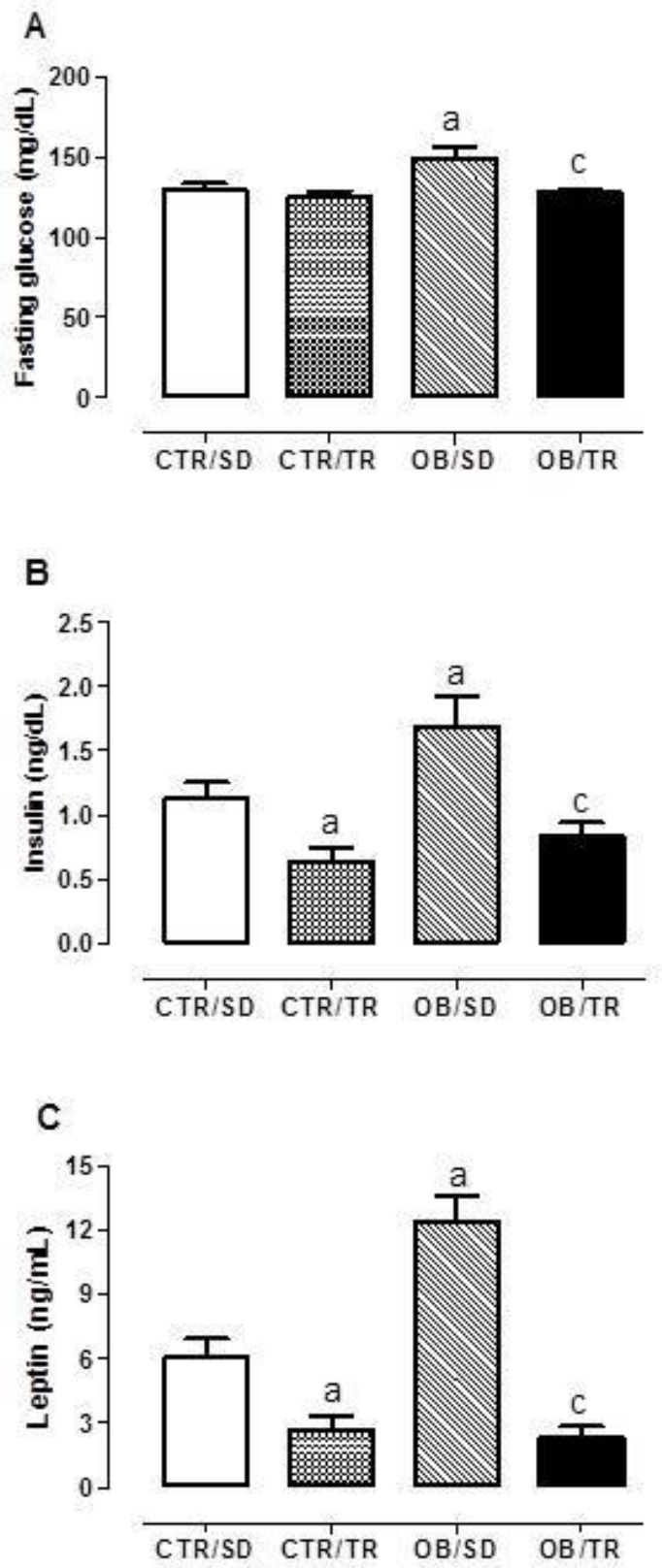

Figure 2. Fasting glucose (panel A), insulin (panel B) and leptin (panel C) from control sedentary (CTR/SD), control trained (CTR/ $\mathrm{TR})$, obese sedentary $(\mathrm{OB} / \mathrm{SD})$ and obese trained $(\mathrm{OB} / \mathrm{TR})$. Data are mean \pm SEM. ANOVA two-way, Bonferroni post test $(P<0.05)$. adifferent from $\mathrm{CTR} / \mathrm{SD}$, ${ }^{\mathrm{c}}$ different from $\mathrm{OB} / \mathrm{SD}$.

\section{Adipocyte area}

Exercised groups had reduced adipocyte area compared with their sedentary counterparts (CTR/TR: - 49\%, OB/TR: 41\%). Representative and quantitative analyses are show in Figure 3. 

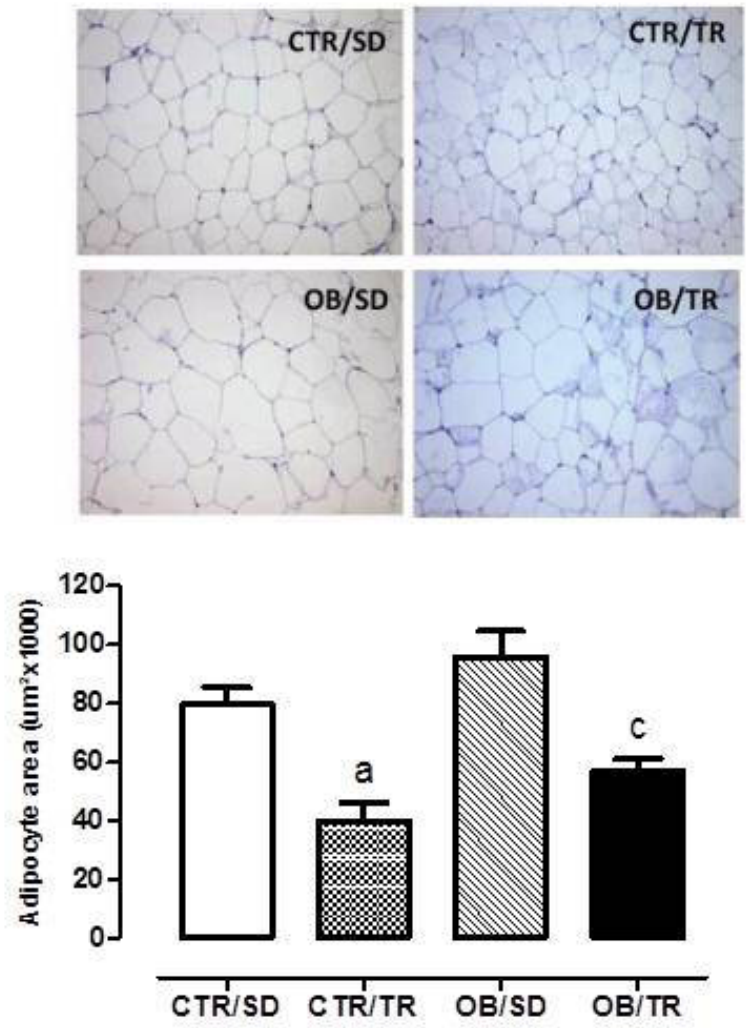

Figure 3. Representative/ quantitative analysis for adipocyte size from control sedentary (CTR/SD), control trained (CTR/TR), obese sedentary $(\mathrm{OB} / \mathrm{SD})$ and obese trained $(\mathrm{OB} / \mathrm{TR})$. Data are mean $\pm \mathrm{SEM}$. ANOVA two-way, Bonferroni post test $(P<0.05)$. ${ }^{a}$ different from $\mathrm{CTR} / \mathrm{SD}$, ${ }^{\mathrm{c}}$ different from $\mathrm{OB} / \mathrm{SD}$.

\section{Discussion}

Our results showed that 7 -week aerobic exercise training was effective in reducing body weight, by approximately $30 \%$, and epididymal fat mass, by approximately $40 \%$, in rats from both exercised groups. The effects of exercise training to prevent body weight gain have also been shown by Levin e DunnMeynell (2004) using 6 weeks of wheel running with 8 weeks high fat and sucrose fed rats. Higa, Spinola, Fonseca-Alaniz e Evangelista, (2014) had showed a reduction in epididymal fat in obese mice trained for 8 weeks of sessions of 60 minutes at $60 \%$ of maximal speed conducted five days per week. A greater use of energy substrates by skeletal muscle increases the demand for supply this energy production (Baker, Mc Cormick, \& Robergs, 2010; Scomparin et al., 2006). Then, these results observed in our study could be explained by the activation of the central nervous system induced by exercise training, which activates sympathetic nervous system and increases the release of catecholamines, which in turn, promotes lipolysis to maintain energy supply in trained animals.

It is well established that exercise training is an important approach to control the content of adipose tissue, especially on visceral fat, which is more susceptible to lipolysis in experimental models (Arner, 1995; Gomes et al., 2010; MorenoEutimio, \& Acosta-Altamirano, 2014; Goyal, Nimmakayala \&
Zonszein, 2014). In agreement with previous studies, our results demonstrated that aerobic exercise training during 7 weeks was efficient in reducing the average area of adipocytes from epididymal fat pad in both trained groups, even when animals were fed with palatable high fat diet. Indeed, previous studies have shown a lower diameter of adipocyte in animals fed with high fat diet or high cholesterol diet and were exercised with moderate continuous exercise either swimming or running wheels for 4 to 8 weeks (Gollisch et al., 2009; Guerra et al., 2007).

In addition to the increase of insulin levels in $\mathrm{OB} / \mathrm{SD}$ group, it was observed an increase in fasting glucose, showing that the high palatable diet turns metabolism to an insulin-resistance state. Possibly, insulin signaling and glucose uptake were improved by exercise training in the OB/TR group. Mechanisms that triggered this result could be related to the increase in glucose transporter (GLUT -4) expression and/or translocation as shown in different studies (Richter \& Hargreaves, 2013; TorresLeal, De Capitani, Tirapegui, 2009). Gomes and colleagues (2012) demonstrated that moderate exercise on a treadmill prevented insulin resistance in obese animal. Additionally they also demonstrated that the same exercise program was efficient to reduce fat pads and normalize glucose tolerance.

Different studies have shown a hypothalamic leptin resistance in obese animals (Koh, Park \& Quon, 2008; Yang, \& Barouch, 2007). Our results demonstrate that the $\mathrm{OB} / \mathrm{SD}$ group had higher levels of leptin compared with the control group. This results was expected in view of the fact that the circulating leptin is proportional to the adipose tissue mass (Farooqi et al., 2002; Ravussin et al., 2014), mainly to visceral adipose tissue since it produces significant amounts of leptin (Coelho, Oliveira \& Fernandes, 2013). In addition, insulin stimulates the production of leptin (Barr et al., 1997; Tsai, Asakawa, Amitani \& Inui, 2012) thus, hyperleptinemia observed in $\mathrm{OB} / \mathrm{SD}$ rats could be related not only to adipocyte size, but also to hyperinsulinemia.

Trained groups had similar levels of leptin, both lower than sedentary counterparts. This result is in accordance with those demonstrated by Estadella and colleagues (2004) in obese rats fed with cafeteria diet and submitted to swimming training for 7 weeks. However, a recent study showed no change in plasma leptin levels after consumption of high fat diet and moderate continuous treadmill training, 5 days a week for 8 weeks (Haghshenas et al., 2014). Exercise training could modulate leptin concentration through different mechanisms. Zhao et al. (2011) demonstrated improvements in hypothalamic leptin signaling in rats submitted to chronic exercise. In the same line of thought, Yi et al. (2013) showed an increase in leptin receptors on liver and vascular smooth muscle. Other studies proposed mechanisms related with reduction on fat pad mass (Estadella et al., 2004; Park et al., 2012).

\section{Conclusion}

The exercise training protocol proposed was effective to prevent adipocyte enlargement and the rise of leptin levels in high palatable diet fed rats. In addition, the insulin level was lower in trained rats demonstrating an improvement of insulin sensitivity. 


\section{References}

Arner, P. (1995). Differences in lipolysis between human subcutaneous and omental adipose tissues. Annals of Medicine, 27(4), 435-438.

Baker, J.S., Mc Cormick, M.C. \& Robergs, R. A. (2010). Interaction among skeletal muscle metabolic energy systems during intense exercise. Journal of Nutrition and Metabolism, 2010:905612.

Barr, V.A., Malide D., Zarnowski M.J., Taylor, S.I. \& Cushman, S. W. (1997). Insulin stimulates both leptin secretion and production by rat white adipose tissue. Endocrinology, 138(10), 4463-4472.

Ciolac, E.G. \& Guimarães, G.V. (2004). Exercício físico e síndrome metabólica. Revista Brasileira de Medicina do Esporte, 10(4), 319-324.

Coelho, M., Oliveira, T. \& Fernandes, R. (2013). Biochemistry of adipose tissue: an endocrine organ. Archives of Medical Science, 9(2), 191-200.

Estadella, D., Oyama, L.M., Dâmaso, A.R., Ribeiro, E.B. \& Oller do Nacimento, C.M. (2004). Effect of palatable hyperlipidic diet on lipid metabolismo of sedentary and exercised rats. Nutrition, 20, 218-224.

Farooqi, I.S., Matarese, G., Lord, G.M., Keogh, J.M., Lawrence, E., Agwu, C., Sanna, V. \& Jebb, S.A. (2002). Beneficial effects of leptin on obesity, T cell hyporesponsiveness, and neuroendocrine/ metabolic dysfunction of human congenital leptin deficiency. Journal of Clinical Investigation, 110, 1093-1103.

Galic, S., Oakhill, J.S. \& Steinberg, G.R. (2010). Adipose tissue as an endocrine organ. Molecular and Cellular Endocrinology,316(2),129-139.

Gollisch, K.S.C., Brandauer, J., Jessen, N., Toyoda, T., Nayer, A., Hirshma, M.F. \& Goodyear, L.J. (2009). Effects of exercise training on subcutaneous and visceral adipose tissue in normal-and high-fat diet-fed rats. American Journal of Physiology and Endocrinology Metabolism, 297, 495-504.

Gomes, F., Telo, D.F., Souza, H.P., Nicolau, J.C., Halpern, A. \& Serrano Jr, C.V. (2010). Obesidade e doença arterial coronariana: papel da inflamação vascular. Arquivos Brasileiros de Cardiologia, 94(2), 273-279.

Gomes, R. M., Marques, A. S., Torrezan, R., Scomparin, D. X., Mathias, P.C. F. \& Rinaldi W. (2012). Effect of moderate exercise program on rats from different models of obesity. Revista da Educação Física /UEM, 23(2), 285-294.

Gordecke, J.H. \& Micklesfield, L.K. (2014). The effect of exercise on obesity, body fat distribution and risk for type 2 diabetes. Medicine and Sport Science, 60, 82-93.

Goyal, A., Nimmakayala, K.R. \& Zonszein, J. (2014). Is there a paradox in obesity? Cardiology in Review, 22(4), 163-170.

Guerra, R.L., Prado, W.L., Cheik, N.C., Viana, F.P., Botero, J.P, Vendramini, R.C., Carlos, I.Z., Rossi, E.A. \& Dâmaso, A.R. (2007). Effects of 2 or 5 consecutive exercise days on adipocyte area and lipid parameters in Wistar rats. Lipids in Health and Disease, 2(6), 16.

Guimarães, D.E., Duque, D.E., De Carvalho, S.F.L., De Moraes, D. \& Carmo, M.G. (2007). Adipocitocinas: uma nova visão do tecido adiposo. Revista de Nutrição, 20(5), 549-559.

Haghshenas, R., Jafari, M., Ravasi, A., Kordi, M., Gilani, N., Shariatzadeh, M., Hedayati, M., \& Rahimi, M. (2014). The effect of eight weeks endurance training and high-fat diet onappetite-regulating hormones in rat plasma. Iranian Journal of Basic Medical Sciences, 17(4), 237-243.
Henninger, A.M.,Eliasson, B., Jenndahl, L.E. \& Hammarstedt, A. (2014). Adipocyte hypertrophy, inflammation and fibrosis characterize subcutaneous adipose tissue of healthy, non-obese subjects predisposed to type 2 diabetes. Plos One, 9(8).

Higa, T.S., Spinola, A.V., Fonseca-Alaniz, M.H. \& Evangelista, F.S. (2014). Remodeling of white adipose tissue metabolism by physical training prevents insulin resistance. Life Science, 103(1), 41-8.

Hohl, R., Ferraresso, R.L.P., De Oliveira, R.B., Lucco, R., Brenzikofer, R. \& De Macedo, D.V. (2009). Development and characterization of an overtraining animal model. Medicine and Science in Sports and Exercise, 41(5), 1155-1163.

Horská, K., Kucerova, J., Suchy, P. \& Kotolova, H. (2014). Metabolic syndrome - dysregulation of adipose tissue endocrine function. Czech and Slovak Pharmacy, 63, 152-159.

Hotamisligi, G., Shargill, N. \& Spilgelman, B.M. (1993). Adipose expression of tumor necrosis factor-alpha: direct role in obesity-linked insulin resistance. Science, 259, 87-91.

Iikuni, N., Lam, Q.L., Lu, L., Matarese, G. \& La Cava, A. (2008). Leptin and Inflammation. Current Immunology Reviews, 4(2), 70-79.

Koh, K.K., Park, S.M. \& Quon, M. J. (2008) Leptin and cardiovascular disease: response to therapeutic interventions. Circulation, 117(25), 3238-3249.

Levin, B.E. \& Dunn-Meynell, A.A. (2004). Chronic exercise lowers the defended body weight gain and adiposity in diet induced obese rats. American Journal Physiology Regulatory Integrative and Comparative Physiology, 286(4), 771-778.

Ma, T., Liaset, B., Hao, Q., Petersen, R.K., Thi, N.E.F, Lillefosse, H.H. \& Ringholm, S. (2011). Sucrose counteracts the anti-inflammatory effect of fish oil in adipose tissue and increases obesity development in mice. Plos One, 6(6).

Moreno-Eutimio, M.A. \& Acosta-Altamirano, G. (2014). Immunometabolism of exercise and sedentary lifestyle. Cirugía y Cirujanos, 82(3), 344-351.

Park, Y., Booth, F.W., Lee, S., Laye, M.J. \& Zhang, C. (2012) Physical activity opposes coronary vascular dysfunction induced during high fat feeding in mice. The Journal of Physiology, 590(17), 4255-4268.

Rask-Madsen, C. \& Kahn, R.C. (2012). Tissue-specific insulin signaling, metabolic syndrome and cardiovascular disease. Arterioclerosis, Thrombosis, and Vascular Biology, 32, 2052-2059.

Ravussin, Y., LeDuc, C.A., Watanabe, K., Mueller, B.R., Skowronski, A., Rosenbaum, M. \& Leibel, R.L. (2014). Effects of chronic leptin infusion on subsequent body weight and composition in mice: Can body weight set point be reset? Molecular Metabolism, 3(4), 432-440.

Richter, E.A. \& Hargreaves, M. (2013). Exercise, GLUT4, and skeletal muscle glucose uptake. Physiological Reviews, 93(3), 993-1017.

Sampey, B.P., Vanhoose, A.M., Winfield, H.M., Freemerman, A.J., Muehlbauer, M. J., Fueger, P.T., Newgard, C.B. \& Makowski L. (2011). Cafeteria diet is a robust model of human metabolic syndrome with liver and adipose inflammation: comparison to high-fat diet. Obesity, 19(6).

Scomparin, D.X., Graciolli, S., Marçal, A.C., Gravena, C., Andreazzi, A.E. \& Mathias, P.C. (2006). Swim training applied at early age is 
critical to adrenal medulla catecholamine content and to attenuate monosodium L-glutamate-obesity onset in mice. Life Science, 79(22), 2251-2156.

Torres-Leal, F.L., De Capitani, M.D., Tirapegui, J. (2009). The effect of physical exercise and caloric restriction on the components of metabolic syndrome. Brazilian Journal of Pharmaceutical Sciences, 45(3).

Tsai, M., Asakawa, A., Amitani, H. \& Inui, A. (2012). Stimulation of leptin secretion by insulin. Indian Journal of Endocrinology and Metabolism, 3, 543-548.

Vachharajani, V. \& Granger D.N. (2009). Adipose tissue: a motor for the inflammation associated with obesity. International Union of Biochemistry and Molecular Biology, 61(4):424-430.

Weisberg, S.P., McCann, D., Desai, M., Rosenbaum, M., Leibel, R.L., Anthony, W. \& Ferrante, A.W Jr. (2003). Obesity is associated with macrophage accumulation in adipose tissue. Journal of Clinical Investigation, 112(12):1796-1808.

Wood, I.S., De Heredía, F.P., Wang, B. \& Trayhurn, P. (2009). Cellular hypoxia and adipose tissue dysfunction in obesity. Procedings of the Nutrition Society, 68(1), 370-377.

Xu, H., Barnes, G.T., Yang, Q.Y., Tan, G., Yang, D., Chou, C.J., Sole, J., Nichols, A., Ross, J.S., Tartaglia, L.A. \& Chen, H. (2003). Chronic inflammation in fat plays a crucial role in the development of obesity-related insulin resistance. Journal of Clinical Investigation, 112, 1821-1830.

Yang, R. \& Barouch, L.A. (2007). Leptin signaling and obesity: cardiovascular consequences. Circulation Research, 101(6), 545-59.

Yi, X., Cao, S., Chang, B., Zhao, D., Gao, H., Wan, Y., Shi, J., Wei, W. \& Guan, Y. (2013). Effects of acute exercise and chronic exercise on the liver leptin-AMPK-ACC signaling pathway in rats with type 2 diabetes. Journal of Diabetes Research, 2013:946432.

Zhang, Y., Proença, R., Maffei, M., Barone, M., Leopold, L. \& Friedman, J. M. (1994). Positional cloning of the mouse obese gene and its human homologue. Nature 372, 425-432.

Zhao, J., Tian, Y., Xu, J., Liu, D., Wang, X., Zhao, B. (2011). Endurance exercise is a leptin signaling mimetic in hypothalamus of Wistar rats. Lipids in Health and Disease, 10, 225.

\section{Author's note}

Nádia F. Garcia, Carmem Peres Valgas da Silva, Maycon Jr. Ferreira are affiliated with the Laboratory of Cardiovascular Physiology and Physical Activity Department. Physical Education, University of São Paulo State - Rio Claro, SP, Brazil.

Leandro K. Oharomari is affiliated with the School of Pharmaceutical Sciences of Araraquara, Department of Food and Nutrition, University of São Paulo State, Araraquara, SP, Brazil.

Thalita Rocha is affiliated with the São Francisco University Medical School, Bragança Paulista, SP, Brazil.

Camila de Moraes is affiliated with the School of Physical Education and Sport of Ribeirão Preto, University of São Paulo, SP, Brazil.

\section{Corresponding author}

Camila de Moraes

School of Physical Education and Sport of Ribeirão Preto, University of São Paulo, SP, Brazil.

Email: camimoraes@usp.br

Manuscript received on October 16, 2014

Manuscript accepted on January 11, 2016

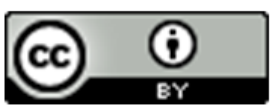

Motriz. The Journal of Physical Education. UNESP. Rio Claro, SP, Brazil - eISSN: 1980-6574 - under a license Creative Commons - Version 3.0 